10. Issa S.Y., Hafez E. M., El-Banna A.S., Abdel Rahman S.M., Mazroua M.K., El-Hamd M.A. Baclofen Systemic Toxicity: Experimental Histopathological and Biochemical Study. Hum Exp Toxicol. 2018; 37 (4): 431-441. ID: 35860782.

11. Lindsay C., Kouzouna A., Simcox C., Pandyan A.D. Pharmacological interventions other than botulinum toxin for spasticity after stroke. Cochrane Database Syst Rev. 2016; 10: CD010362. DOI: 10.1002/14651858.CD010362.pub2

12. Reynolds K., Kaufman R., Korenoski A., Fennimore L., Shulman J., Lynch M. Trends in gabapentin and baclofen exposures reported to U.S. poison centers. Clinical Toxicology. 2020; 58 (7): 763-772.

\title{
Иманов Э.А. \\ Использование современных препаратов в комплексном лечении и профилактика воспалительных заболеваний пародонта у детей
}

\author{
Азербайджанский Медииинский Университет
}

(Азербайджан, Баку)

doi: $10.18411 / s r-10-06-2021-04$

\section{Abstract}

In the study process participated schoolchildren with diagnosis of chronic catarrhal gingivitis (HKG) and chronic periodontitis light form (HPLC). In total 103 patient, 67 patient with chronic catarrhal gingivitis and 36 patient with chro nic periodontitis light form. The laboratory results showed that in the process of conducting treatment and preventive measures during the use of the drug Loroben the functional activity of the local immune factors were significantly restored. If we pay attention to indicators after professional hygiene and local application of a solution of digluconate of chlorhexidine, after treatment with Loroben values significantly increased. Solution of Loroben improves trophic of the periodontal tissues, promotes the elimination of bleeding gums and inflammation, and these promotes positive treatment outcome.

Keywords: catarrhal gingivitis, chronic periodontitis, Loroben

Профилактика и лечение заболеваний пародонта, с участием детской стоматологии, остается одной из важнейших проблем современной стоматологии. Это связано с широким распространением среди населения тяжелых последствий, причинами которых являются как нарушения функций в челюстно-лицевой области, так и изменения в общем статусе больного. [2, 4]. Традиционно, в лечении и профилактике заболеваний пародонта используются антибактериальные, противовоспалительные, гормональные и другие препараты. Как известно, длительное использование этих препаратов, на примере популяции детей из пригорода, может привести к дисбактериозу микрофлоры полости рта, снижению общей резистентности и к другим тяжелым последствиям [1,3].

Цель. Оценка эффективности препарата Лоробен в комплексном лечении воспалительных заболеваний пародонта у детей.

Методы. У детей различного возраста лечение и профилактика заболеваний пародонта до настоящего времени вызывает затруднения. Отсюда следует, что в выделенных группах риска, по вопросам диагностики и лечения необходима реализация четких организационных мероприятий.

В процессе исследуемого лечения принимали участие 103 больных с диагнозом хронический катаральный гингивит (ХКГ) и хронический пародонтит легкой степени (ХПЛС). Из них 67 человек были больны хроническим катаральным гингивитом и 36 человек - хроническим пародонтитом легкой степени.

Больные были разделены на 3 группы наблюдения:

I группа - больные, которым никогда не назначались лечебные мероприятия, проводилась только профессиональная гигиена полости рта.

II группа - больные, у которых после проведения профессиональной гигиены полости рта использовался раствор хлоргексидина биглюконат. 
III группа - у которых после проведения профессиональной гигиены полости рта применялся препарат Лоробен.

При лечении хронического катарального гингивита группы были разделены: 12 детей, которым проводилась профессиональная гигиена полости рта; 20 детей, у которых использовался раствор хлоргексидина биглюконат и 35 детей, которым применялся препарат Лоробен.

Для лечения хронического пародонтита легкой степени у 12 детей проводилась профессиональная гигиена полости рта; у 10 - применялся раствор хлоргексидина биглюконат; у 14 - препарат Лоробен.

Результаты лечебно-профилактических мероприятий в каждой из 3 групп оценивались на основе клинических наблюдений и объективных тестов [коэффициентам OHİ-S, PMA,Рİ и индексу SBİ].

Кроме этого, исследовались микрофлора пародонтальных карманов и параметры местного иммунитета больных.

Количество иммуноглобулинов ( $\operatorname{sgA}, \operatorname{IgG})$ смешанных со слюной определялись методом радиальной иммунодиффузии основанной Манчини. Активность, смешанного со слюной лизоцима определялась нефелометрическим методом. Эта данные были получены до лечебно-профилактических мероприятий и в ходе лечения.

Результаты и обсуждение. В результате лечебно-профилактических мероприятий, наблюдали в динамике произошедшие изменения в полости рта. Анализ соответствующих стоматологических индексов показал, что после применения препарата Лоробен в течение более чем 3-х дней в оценке индексов наблюдаются значительные изменения (таблица 1)

Таблица 1.

Динамика показателей стандартных клинических индексов у пащиентов с ХКГ после местного введения препарата Лоробен

\begin{tabular}{|l|l|l|l|l|l|}
\hline \multirow{2}{*}{$\begin{array}{c}\text { Клини- } \\
\text { ческие } \\
\text { индексы }\end{array}$} & \multirow{2}{*}{$\begin{array}{c}\text { До } \\
\text { лечения }\end{array}$} & \multicolumn{4}{|c|}{ Динамика лечения } \\
\cline { 3 - 6 } & & \multicolumn{1}{|c|}{3 дня } & \multicolumn{1}{|c|}{5 дней } & \multicolumn{1}{|c|}{7 дней } & \multicolumn{1}{|c|}{14 дней } \\
\hline \multirow{2}{*}{ OHİ-S } & $2,24 \pm 0,19$ & $1,05 \pm 0,06$ & $0,58 \pm 0,04$ & $0,24 \pm 0,02$ & $0,12 \pm 0,01$ \\
& $(1,1-3)$ & $(0,4-2) * * *$ & $(0,1-1,3) * * *$ & $(0-0,8) * * *$ & $(0-0,4) * * *$ \\
\hline \multirow{2}{*}{ PMA, \% } & $53,8 \pm 4,3$ & $20,6 \pm 1,8$ & $12,4 \pm 1,1$ & $7,8 \pm 0,6$ & $5,6 \pm 0,4$ \\
& $(41-66)$ & $(30-31) * * *$ & $(8-21) * * *$ & $(4-15) * * *$ & $(2-12) * * *$ \\
\hline \multirow{2}{*}{ SBİ } & $1,68 \pm 0,12$ & $1,07 \pm 0,09$ & $0,65 \pm 0,05$ & $0,26 \pm 0,01$ & $0,10 \pm 0,01$ \\
& $(1,3-3,2)$ & $(0,5-1,8) * * *$ & $(0,3-1,2) * * *$ & $(0-0,8) * * *$ & $(0-0,4) * * *$ \\
\hline \multirow{2}{*}{ Pİ } & $1,69 \pm 0,12$ & $1,23 \pm 0,09$ & $0,96 \pm 0,05$ & $0,32 \pm 0,02$ & $0,11 \pm 0,01$ \\
& $(1,1-3,5)$ & $(0,8-1,6) * *$ & $(0,5-1,4) * * *$ & $(0,1-0,9) * * *$ & $(0-0,3) * * *$ \\
\hline
\end{tabular}

Примечание: показатели до лечения и после различались статистически достоверно * $-p<0,05 ; * *-p<0,01 ; * * *-p<0,001$ (по критерию У-Уилкоксона).P - уровень статистически значимого различия по сравнению с начальной оценкой [до начала лечения]

У детей с диагнозом хронический катаральный гингивит до лечения индекс ОНІं-

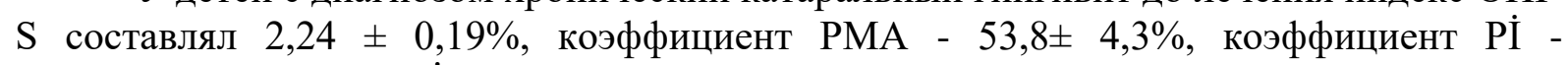

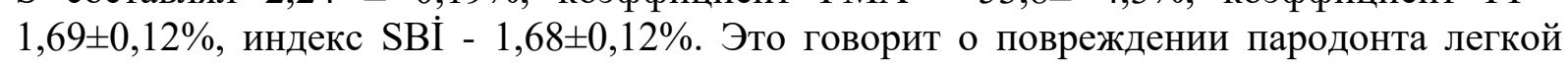
степени.

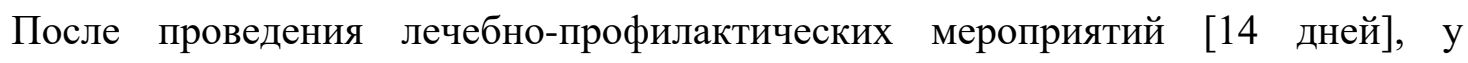
большей части детей, включенных в основную группу, отмечались значительные

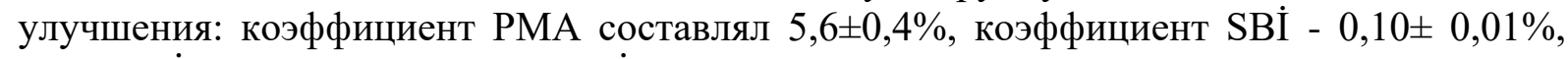

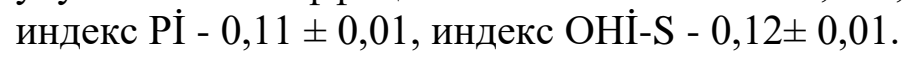

У детей с диагнозом хронический пародонтит легкой степени до лечения индекс

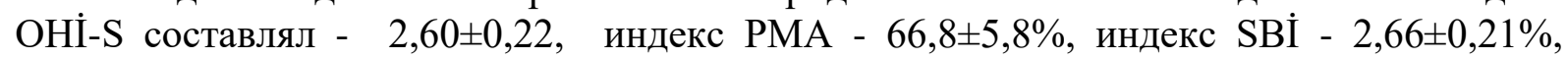

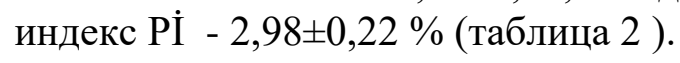


Таблииа 2.

Динамика показателей стандартных клинических индексов у паџиентов с ХПЛС после местного нанесения препарата Лоробен

\begin{tabular}{|c|c|c|c|c|c|}
\hline \multirow{2}{*}{$\begin{array}{c}\text { Клини- } \\
\text { ческие } \\
\text { индексы }\end{array}$} & \multirow{2}{*}{ До лечения } & \multicolumn{4}{|c|}{ Динамика лечения } \\
\hline & & 3 дня & 5 дней & 7 дней & 14 дней \\
\hline OHİ-S & $\begin{array}{l}2,60 \pm 0,22 \\
(1,1-3)\end{array}$ & $\begin{array}{l}1,10 \pm 0,10 \\
(0,6-1,8) * * *\end{array}$ & $\begin{array}{l}0,72 \pm 0,05 \\
(0,4-1,4) * * *\end{array}$ & $\begin{array}{l}0,51 \pm 0,03 \\
(0,2-1) * * *\end{array}$ & $\begin{array}{l}0,31 \pm 0,02 \\
(0,1-0,6) * * *\end{array}$ \\
\hline PMA, \% & $\begin{array}{l}66,6 \pm 5,8 \\
(51-75) \\
\end{array}$ & $\begin{array}{l}34,2 \pm 2,2 \\
(25-45) * * *\end{array}$ & $\begin{array}{l}16,8 \pm 1,4 \\
(24-36) * * *\end{array}$ & $\begin{array}{l}11,2 \pm 1,0 \\
(7-19) * * *\end{array}$ & $\begin{array}{l}9,3 \pm 0,8 \\
(5-16) * * *\end{array}$ \\
\hline SBİ & $\begin{array}{l}2,66 \pm 0,21 \\
(1,4-3,8) \\
\end{array}$ & $\begin{array}{l}2,11 \pm 0,16 \\
(1,3-3,2) *\end{array}$ & $\begin{array}{l}2,06 \pm 0,15 \\
(1,2-3) *\end{array}$ & $\begin{array}{l}1,81 \pm 0,14 \\
(0,8-2,6) * *\end{array}$ & $\begin{array}{l}0,56 \pm 0,04 \\
(0,2-1,2) * * *\end{array}$ \\
\hline Pİ & $\begin{array}{l}2,98 \pm 0,22 \\
(2-4,1)\end{array}$ & $\begin{array}{l}2,85 \pm 0,20 \\
(1,8-3,9) \\
\end{array}$ & $\begin{array}{l}2,33 \pm 0,18 \\
(1,2-3,4) *\end{array}$ & $\begin{array}{l}1,93 \pm 0,14 \\
(1-3) * * *\end{array}$ & $\begin{array}{l}0,44 \pm 0,03 \\
(0,2-1,1) * * *\end{array}$ \\
\hline
\end{tabular}

Примечание: показатели до лечения и после различались статистически достоверно * $-p<0,05 ; * *-p<0,01 ; * * *-p<0,001$ (по критерию У-Уилкоксона).

$P$ - уровень статистически значимого различия по сравнению с начальной оченкой [до начала лечения]

Гигиеническое состояние полости рта также весьма улучшилось.

У пациентов с диагнозом ХКГ после чистки зубных отложений и непосредственно после обработки зубо-десневой борозды препаратом Лоробен, в качественном составе микроорганизмов и в количественных показателях наблюдались существенные изменения. Если, перед началом лечения встречались 9 основных видов пародонтопатогенных микроорганизмов, то после проведения лечебных мероприятий, был обнаружен только один часто встречаемый микроорганизм Bacteriodes forsythus (таблица 3).

Таблииа 3.

Динамика численности пародонтопатогенных представителей в десневой борозде пациентов с хроническим катаральным гингивитом до и после местного применения препарата Лоробен

\begin{tabular}{|c|c|c|c|c|}
\hline \multirow{2}{*}{ Микроорганизмы } & \multirow{2}{*}{ До лечения } & \multicolumn{3}{|c|}{ Динамика лечения } \\
\hline & & 3 дня & 7 дней & 14 дней \\
\hline Streptococcus intermedius & $\begin{array}{l}6,6 \pm 0,4 \\
(0-9) \\
\end{array}$ & $\begin{array}{l}4,6 \pm 0,3 \\
(0-7) * * *\end{array}$ & $\begin{array}{l}2,8 \pm 0,2 \\
(0-5) * * *\end{array}$ & $\begin{array}{l}0,8 \pm 0,1 \\
(0-2) * * *\end{array}$ \\
\hline Streptococcus mitis & $\begin{array}{l}8,5 \pm 0,7 \\
(0-12)\end{array}$ & $\begin{array}{l}3,1 \pm 0,3 \\
(0-7) * * *\end{array}$ & $\begin{array}{l}1,8 \pm 0,1 \\
(0-5) * * *\end{array}$ & $\begin{array}{l}0,6 \pm 0,1 \\
(0-2) * * *\end{array}$ \\
\hline Streptococcus sangius & $\begin{array}{l}6,7 \pm 0,5 \\
(0-8)\end{array}$ & $\begin{array}{l}2,7 \pm 0,2 \\
(0-5) * * *\end{array}$ & $\begin{array}{l}2,2 \pm 0,2 \\
(0-4) * * *\end{array}$ & $\begin{array}{l}0,6 \pm 0,1 \\
(0-2) * * *\end{array}$ \\
\hline Prevotella intermedia & $\begin{array}{l}8,2 \pm 0,7 \\
(0-13)\end{array}$ & $\begin{array}{l}3,4 \pm 0,3 \\
(0-7) * * *\end{array}$ & $\begin{array}{l}1,9 \pm 0,1 \\
(0-5) * * *\end{array}$ & $\begin{array}{l}0,7 \pm 0,1 \\
(0-2) * * *\end{array}$ \\
\hline Prevotella melaninogenica & $\begin{array}{l}8,1 \pm 0,7 \\
(0-13)\end{array}$ & $\begin{array}{l}5,1 \pm 0,4 \\
(0-9) * * *\end{array}$ & $\begin{array}{l}1,7 \pm 0,1 \\
(0-5) * * *\end{array}$ & $\begin{array}{l}0,3 \pm 0,1 \\
(0-2) * * *\end{array}$ \\
\hline Actinomuces spp. & $\begin{array}{l}6,2 \pm 0,5 \\
(0-8)\end{array}$ & $\begin{array}{l}4,2 \pm 0,4 \\
(0-7) * *\end{array}$ & $\begin{array}{l}2,2 \pm 0,2 \\
(0-5) * * *\end{array}$ & $\begin{array}{l}0,8 \pm 0,1 \\
(0-2) * * *\end{array}$ \\
\hline Bacteriodes forsythus & $\begin{array}{l}6,6 \pm 0,4 \\
(0-8)\end{array}$ & $\begin{array}{l}2,3 \pm 0,2 \\
(0-6) * * *\end{array}$ & $\begin{array}{l}1,8 \pm 0,1 \\
(0-3) * * *\end{array}$ & $\begin{array}{l}0 \\
* * * \\
\end{array}$ \\
\hline $\begin{array}{l}\text { Actinobacillis actinomycetem } \\
\text { comitans }\end{array}$ & $\begin{array}{l}4,9 \pm 0,3 \\
(0-8)\end{array}$ & $\begin{array}{l}3,1 \pm 0,2 \\
(0-7) * * *\end{array}$ & $\begin{array}{l}2,1 \pm 0,2 \\
(0-6) * * *\end{array}$ & $\begin{array}{l}0,9 \pm 0,1 \\
(0-2) * * *\end{array}$ \\
\hline Fusobacterium nucleatum & $\begin{array}{l}6,6 \pm 0,5 \\
(0-10)\end{array}$ & $\begin{array}{l}3,2 \pm 0,3 \\
(0-7) * * *\end{array}$ & $\begin{array}{l}2,3 \pm 0,2 \\
(0-5) * * *\end{array}$ & $\begin{array}{l}1,0 \pm 0,1 \\
(0-2) * * *\end{array}$ \\
\hline
\end{tabular}

Примечание: показатели до лечения и после различались статистически достоверно * $-p<0,05 ; * *-p<0,01 ; * * *-p<0,001$ (по критерию У-Уилкоксона). 
Количественные показатели в отношении вышеотмеченных микроорганизмов в значительной степени снизились. В период лечения зубо-десневой борозды препаратом Лоробен, после проведенной 14 дневной регулярной обработки антисептиком в зубодесневой борозде, в динамике общей численности пародонтопатогенных микроорганизмов наблюдались значительные снижения. Не были обнаружены даже Bacteriodes forsythus.

При лечении хронического пародонта легкой степени после очистки зубных отложений и пародонтальных карманов, последующая обработка препаратом Лоробен была существенно эффективна в отношении всех микроорганизмов (таблица 4).

Таблица 4.

Динамика численности пародонтопатогенных представителей в пародонтальных карманах паџиентов с ХПЛС после местного применения препарата Лоробен

\begin{tabular}{|c|c|c|c|c|}
\hline \multirow{2}{*}{ Микроорганизмы } & \multirow{2}{*}{ До лечения } & \multicolumn{3}{|c|}{ Динамика лечения } \\
\hline & & 3 дня & 7дней & 14 дней \\
\hline Streptococcus intermedius & $\begin{array}{l}8,8 \pm 0,8 \\
(0-12) \\
\end{array}$ & $\begin{array}{l}4,7 \pm 0,3 \\
(0-6) * * *\end{array}$ & $\begin{array}{l}3,1 \pm 0,2 \\
(0-5) * * *\end{array}$ & $\begin{array}{l}1,8 \pm 0,1 \\
(0-3) * * *\end{array}$ \\
\hline Streptococcus mitis & $\begin{array}{l}10,1 \pm 0,9 \\
(0-14)\end{array}$ & $\begin{array}{l}4,8 \pm 0,4 \\
(0-7) * * *\end{array}$ & $\begin{array}{l}3,3 \pm 0,3 \\
(0-5) * * *\end{array}$ & $\begin{array}{l}1,7 \pm 0,1 \\
(0-4) * * *\end{array}$ \\
\hline Streptococcus sangius & $\begin{array}{l}8,0 \pm 0,8 \\
(0-12) \\
\end{array}$ & $\begin{array}{l}3,8 \pm 0,3 \\
(0-6) * * *\end{array}$ & $\begin{array}{l}1,9 \pm 0,2 \\
(0-3) * * *\end{array}$ & $\begin{array}{l}1,2 \pm 0,1 \\
(0-2) * * *\end{array}$ \\
\hline Prevotella intermedia & $\begin{array}{l}10,2 \pm 0,9 \\
(0-13)\end{array}$ & $\begin{array}{l}4,8 \pm 0,3 \\
(0-7) * * *\end{array}$ & $\begin{array}{l}2,5 \pm 0,1 \\
(0-4) * * *\end{array}$ & $\begin{array}{l}1,0 \pm 0,1 \\
(0-2) * * *\end{array}$ \\
\hline Prevotella melaninogenica & $\begin{array}{l}10,2 \pm 0,9 \\
(0-13)\end{array}$ & $\begin{array}{l}4,4 \pm 0,4 \\
(0-8) * * *\end{array}$ & $\begin{array}{l}2,7 \pm 0,3 \\
(0-5) * * *\end{array}$ & $\begin{array}{l}1,2 \pm 0,1 \\
(0-2) * * *\end{array}$ \\
\hline Actinomuces spp. & $\begin{array}{l}9,8 \pm 0,9 \\
(0-13)\end{array}$ & $\begin{array}{l}3,6 \pm 0,4 \\
(0-7) * * *\end{array}$ & $\begin{array}{l}1,3 \pm 0,1 \\
(0-3) * * *\end{array}$ & $\begin{array}{l}1,1 \pm 0,1 \\
(0-3) * * *\end{array}$ \\
\hline Bacteriodes forsythus & $\begin{array}{l}8,1 \pm 0,8 \\
(0-10)\end{array}$ & $\begin{array}{l}3,1 \pm 0,1 \\
(0-5) * * *\end{array}$ & $\begin{array}{l}2,2 \pm 0,1 \\
(0-4) * * *\end{array}$ & $\begin{array}{l}1,3 \pm 0,1 \\
(0-3) * * *\end{array}$ \\
\hline $\begin{array}{l}\text { Actinobacillis } \\
\text { actinomycetem comitans }\end{array}$ & $\begin{array}{l}8,7 \pm 0,8 \\
(0-11)\end{array}$ & $\begin{array}{l}3,7 \pm 0,3 \\
(0-8) * * *\end{array}$ & $\begin{array}{l}1,7 \pm 0,1 \\
(0-3) * * *\end{array}$ & $\begin{array}{l}1,2 \pm 0,1 \\
(0-2) * * *\end{array}$ \\
\hline Fusobacterium nucleatum & $\begin{array}{l}9,8 \pm 0,8 \\
(0-12)\end{array}$ & $\begin{array}{l}3,1 \pm 0,3 \\
(0-7) * * *\end{array}$ & $\begin{array}{l}2,1 \pm 0,1 \\
(0-4) * * *\end{array}$ & $\begin{array}{l}1,5 \pm 0,1 \\
(0-3) * * *\end{array}$ \\
\hline
\end{tabular}

Примечание: показатели до лечения и после различались статистически достоверно * $-p<0,05 ; * *-p<0,01$;

Таким образом, в отношении основных видов пародонтопатогенной флоры эффективно применение раствора препарата Лоробен.

Результаты лабораторных исследований показали, что в процессе проведения лечебно-профилактических мероприятий во время использования препарата Лоробен была значительно восстановлена функциональная активность местных иммунных факторов. Если принять во внимание показатели после как профессиональной гигиены, так и местного применения раствора хлоргексина биглюконата, то после лечения препаратом Лоробен значения показателей заметно увеличились.

Выводы. С использованием раствора Лоробен проводимые лечебнопрофилактические мероприятия были эффективны. Раствор Лоробен улучшает трофику тканей пародонта, способствует ликвидации кровоточивости десен и воспаления, а значит, способствует положительному исходу лечения.

$$
* * *
$$

1. Алимский А.В., Флейшер Г.М. Современные предпосылки и реальные возможности для организации гигиенического обучения и стоматологического просвещения среди детского населения России // Медицинский алфавит. Стоматология, 2010, №3, с.21-24 
2. Булгакова А.И. Клинико- микробиологическое обоснование комплексного лечения больных пародонтитом со средней и тяжелой степени тяжести с учетом молекулярно-генетической характеристики микробиоты полости рта // Пародонтология. -2017. - Т.22, №1.-С.70-73

3. Грудянов А.И. Средства и методы профилактики воспалительных заболеваний пародонта. М., 2012, $336 \mathrm{c}$.

4. Sharva V., Reddy V., Bhambal A., Agrawal R. Prevalence of Gingivitis among Children of Urban and Rural Areas of Bhopal District, İndia //J.Clin. Diagn. Res.-2014. - № 8(11).-P.52-4

\section{Леваков С.А., Мушкюрова Д.Р., Обухова Е.А. \\ Возможность применения тест-систем для самостоятельного забора материала на ВПЧ в рамках скрининга рака шейки матки}

ФГАОУ ВО Первый Московский государственный медицинский университет имени И.М. Сеченова Министерства здравоохранения Российской Федераџии

(Россия, Москва)

doi: $10.18411 / s r-10-06-2021-05$

\section{Аннотация}

Рак шейки матки многие годы занимает 2-е место по частоте среди злокачественных новообразований органов репродуктивной системы, уступая лишь раку молочной железы [1]. За открытие роли ВПЧ высокого канцерогенного риска в возникновении рака шейки матки, немецкому ученому Харальду цур Хаузену присуждена Нобелевская премия по физиологии и медицине в 2008 году. Роль ВПЧ в возникновении предраковых процессов и РШМ общепризнана [2-4]. ВПЧ способен вызывать пролиферацию и малигнизацию эпителия кожи и слизистых оболочек [ 5]. Сегодня диагностика ВПЧ находит свое основное применение в программах скрининга, и всё большее число стран дополняют цитологию шейки матки молекулярным тестированием на ВПЧ. Однако многие женщины не участвуют в программах скрининга по причине неудобства, отсутствия информированности, свободного времени и дискомфорта, особенно пожилые пациенты. Рутинный скрининг бессимптомных женщин является главным путем профилактики развития рака шейки матки. В странах, с организованным контролируемым скринингом доля охвата женского населения, подлежащего исследованию, достигает до 90 \% и эффективность скрининга очень высока, тогда как при проведении неконтролируемого скрининга доля охвата женщин не превышает 30-35 \%. При таком низком охвате в скрининге трудно рассчитывать на снижение показателей заболеваемости и смертности от рака шейки матки [6].

В последние годы в клинической практике получили распространение тесты для самостоятельного забора материала на ВПЧ. Тестирование на ВПЧ с помощью образцов, собранных самостоятельно, привлекло внимание из-за его потенциала увеличить число участников скрининговых программ и возможности раннего выявления диспластических процессов шейки матки.

Ключевые слова: рак шейки матки, программы скрининга, CIN, вирус папилломы человека, тесты для самозабора.

Цель

Изучить возможность применения и достоверность тест-систем для самостоятельного забора материала на ВПЧ.

\section{Материалы и методы}

Ретроспективно изучены амбулаторные карты 83 женщин, в возрасте от 18 до 45 лет, проживающих в г. Москва, состоящих на учете в ГКБ 85 и в лечебнореабилитационном центре Минэкономразвития России. Женщины с положительными результатами на ВПЧ-ВКР были приглашены для самостоятельного забора материала на ВПЧ методом ПЦР. 